\title{
Potential Effects of Diurnal Temperature Oscillations on Potato Late Blight with Special Reference to Climate Change
}

\author{
S. K. Shakya, E. M. Goss, N. S. Dufault, and A. H. C. van Bruggen
}

First, second, third, and fourth authors: Department of Plant Pathology, IFAS, University of Florida, Gainesville 32611; and second and fourth authors: Emerging Pathogens Institute, University of Florida, Gainesville 32610. Accepted for publication 15 August 2014.

\section{ABSTRACT}

Shakya, S. K., Goss, E. M., Dufault, N. S., and van Bruggen, A. H. C. 2015. Potential effects of diurnal temperature oscillations on potato late blight with special reference to climate change. Phytopathology 105:230238.

Global climate change will have effects on diurnal temperature oscillations as well as on average temperatures. Studies on potato late blight (Phytophthora infestans) development have not considered daily temperature oscillations. We hypothesize that growth and development rates of $P$. infestans would be less influenced by change in average temperature as the magnitude of fluctuations in daily temperatures increases. We investigated the effects of seven constant $\left(10,12,15,17,20,23\right.$, and $\left.27^{\circ} \mathrm{C}\right)$ and diurnally oscillating ( \pm 5 and $\pm 10^{\circ} \mathrm{C}$ ) temperatures around the same means on number of lesions, incubation period, latent period, radial lesion growth rate, and sporulation intensity on detached potato leaves inoculated with two $P$. infestans isolates from clonal lineages US-8 and US-23. A fourparameter thermodynamic model was used to describe relationships between temperature and disease development measurements. Incubation and latency progression accelerated with increasing oscillations at low mean temperatures but slowed down with increasing oscillations at high mean temperatures $(P<0.005)$, as hypothesized. Infection efficiency, lesion growth rate, and sporulation increased under small temperature oscillations compared with constant temperatures but decreased when temperature oscillations were large. Thus, diurnal amplitude in temperature should be considered in models of potato late blight, particularly when predicting effects of global climate change on disease development.

Additional keywords: diurnal temperature range, epidemic components, optimum curve, Solanum tuberosum.
The effect of temperature on plant disease development has returned to the limelight as the impacts of global warming are increasingly felt $(7,13-17,20,34,42)$. The most recent predictions of increases in global surface temperatures range between 1.5 and $2.0^{\circ} \mathrm{C}$ by the end of the 21 st century compared with last century (45). These projected average increases are lower than those predicted 6 years earlier (43), but changes in climate are unevenly distributed over the globe, with the highest increases in average temperatures at high latitudes in the Northern hemisphere and at high altitudes. Overall, the numbers of extreme temperature and rainfall events as well as the number of drought periods are expected to increase, although the predictions of seasonal and interannual variations in temperatures and precipitation are still erratic (45). Predictions of the daily variations in temperature at particular locations are similarly erratic (32).

Climate change will likely influence plant disease development. Thus far, researchers have mainly made qualitative prognoses about potential effects of climate change on plant diseases (14, 33 ). Due to the complexity of potential effects, most predictions have been based on the average future climate. For example, in Northern countries a milder and more humid climate would stimulate the production of warmer-climate crops, but many pathogens and pests may survive better in the winter and reproduce faster during the cropping season, resulting in an overall increase in pest and disease pressure $(3,20,21)$. Potential effects of climate change on plant disease development have seldom been assessed using detailed quantitative models that take various epidemic

Corresponding author: A. H. C. van Bruggen; E-mail address: ahcvanbruggen@ufl.edu

http://dx.doi.org/10.1094/PHYTO-05-14-0132-R

(c) 2015 The American Phytopathological Society components into account $(15,21,24,27)$. Models predicting the risk of establishment of foliar pathogens in a new area are typically based on average climatic variables such as temperature, rainfall, and humidity. For potato late blight, an empirical model was based on thermal time (in degree-days) to predict the date of planting and emergence of potato and on thermal time on rainy days to predict the first late blight outbreak of the season (24). Results from this model indicate that an increase in mean temperature in northern Europe of $1{ }^{\circ} \mathrm{C}$ will extend the period when chemical control for potato late blight is necessary by 10 to 20 days (24). Moreover, a simulation model has been used to assess potato late blight development in the Andes under climate change scenarios, including expected mean temperature and rainfall (1).

However, global warming will change not only the average temperature and rainfall but also the magnitude (amplitude) of daily oscillations in temperature and the frequency of meteorological extremes (45). In some areas, the daily minimum and maximum temperatures are both expected to increase; in many areas the daily minimum temperature is expected to increase whereas the daily maximum temperature will remain unchanged, resulting in a decrease in temperature amplitude. In some other areas, like high-altitude regions, the daily maximum temperature may increase more than the daily minimum temperature if cloud cover is reduced, increasing the daily temperature amplitude (45). Thus, modeling effects of diurnal variation in temperature and relative humidity or leaf wetness on disease development may be at least as important as modeling average daily temperature and humidity $(18,36,37)$. Based on the results of a simple mathematical model, it was hypothesized that when temperature amplitude is high, the change in relative growth and development rates of plant pathogens in response to an increase in average temperature would be less than that expected under constant temperatures 
(37). However, this hypothesis has not been tested by experimental data. To the best of our knowledge, all controlled experiments to determine the optimum temperature for in vitro growth, infection, and sporulation of plant pathogens have been conducted under constant or alternating high and low temperatures, but not under realistic oscillating temperatures $(1,19,22,29)$.

Potato late blight has become increasingly problematic in many parts of the world. One reason may be the appearance of more aggressive isolates of $P$. infestans (11). Another reason may be a change in climate, particularly in regions highly sensitive to the changing climate, such as the Andes region in Latin America $(12,24)$. To better predict potential effects of climate change on potato production systems, we examined the effect of changes in diurnal temperatures on all stages of the infection cycle of $P$. infestans. A total of 42 short-term experiments were carried out in growth chambers with constant or oscillating temperatures to determine temperature effects on number of lesions formed, incubation and latent periods, lesion expansion rates, and sporulation intensities of two isolates of $P$. infestans on susceptible potato (Solanum tuberosum L.) cultivar Red Lasoda. The objective of this research was to confirm or refute, for $P$. infestans, the general hypothesis put forward by Scherm and van Bruggen (37) that the optimum temperature curve for various growth and development rates of plant pathogens would be steeper under conditions of constant compared to oscillating daily temperatures. We discuss the implications of our results for epidemiological modeling and predicting the potential effects of global climate change on late blight epidemics.

\section{MATERIALS AND METHODS}

Clonal lineages of $\boldsymbol{P}$. infestans. Two isolates representing clonal lineages US-8 and US-23 were used in the experiments. The US-8 clonal lineage was first detected in the United States in 1992, whereas US-23 is a relatively new and currently dominant clonal lineage $(10,11)$. The US-8 isolate US110063 was collected in 2011 from potato in Erie County, PA, and obtained from the $P$. infestans culture collection at Cornell University, Ithaca, NY. The US-23 strain was isolated from a tomato leaf from Homestead, FL, in the spring of 2013. Tomato leaves with typical late blight lesions were cut and plated in pimaricin + ampicillin + rifampicin + PCNB agar (PARP) (2) for isolation. When the colony covered half of the medium, it was transferred to freshly prepared $1.5 \%$ pea agar (120 g of frozen pea, $15 \mathrm{~g}$ of agar, 1,000 $\mathrm{ml}$ of water) for sporulation. The clonal lineage was confirmed by genotyping simple sequence repeat loci (26). Both clonal lineages were transferred to freshly prepared $1.5 \%$ pea agar in a laminar flow biosafety cabinet (BSL2) and maintained at $18^{\circ} \mathrm{C}$.

Plant production. A late-blight-susceptible cultivar, Red Lasoda (Garden Harvest Supply Company, Berne, IN), was used for all experiments. The plants were grown in a greenhouse at temperatures ranging from 18 to $25^{\circ} \mathrm{C}$ without supplemental light. The day length ranged from 10 to $14 \mathrm{~h}$, and the relative humidity from 41 to $98 \%$ depending on the time of the year. Plants were watered daily and fertilized with $7 \mathrm{~g}$ of slow-release pellets of Osmocote $(\mathrm{N} / \mathrm{P} / \mathrm{K}=14: 14: 14)$ once per month.

Inoculum production. Inoculum was produced on leaflets of cultivar Red Lasoda incubated for one week in an incubator at $18^{\circ} \mathrm{C}$ with $12 \mathrm{~h}$ of light. Fully expanded nonterminal leaflets of 4- to 6-month-old plants were placed abaxial surface up in a moist chamber (9-cm diameter petri plate with moistened filter paper on the bottom) and inoculated with sporangia collected from a 2-weekold culture maintained on pea agar (as described above). Sporangia for inoculation were collected from leaflets that had been inoculated 7 days earlier, and the concentration of sporangia per milliliter was adjusted to $20,000 \mathrm{ml}^{-1}$ using a hemocytometer. Sporangial suspensions were placed in a refrigerator at $4^{\circ} \mathrm{C}$ for $40 \mathrm{~min}$ to initiate zoospore production and release. The numbers of zoospores per sporangium were determined using a light microscope.

Inoculation and incubation. For measurement of five epidemic components of late blight (Table 1), 6- to 8-week-old leaves were inoculated in a petri plate moist chamber with the sporangial suspension produced as described earlier. Each petri plate contained two leaflets with the abaxial surface placed upward. Three to four petri plates per isolate were used. The drop inoculation method was followed, where each leaflet was inoculated with $50 \mu \mathrm{l}$ of sporangial suspension. The number of zoospores per sporangium was calculated separately for US-8 and US-23 isolates to get an approximate estimate of zoospore release. The US-23 isolate had a slightly higher average zoospore

TABLE 1. Preliminary experiments comparing epidemic components of late blight on potato with two isolates of Phytophthora infestans in two incubators and one growth chamber at two temperatures under the same lighting conditions ( $12 \mathrm{~h}$ light and $12 \mathrm{~h}$ dark; light intensity 2,200 to 2,400 lx)

\begin{tabular}{|c|c|c|c|c|c|}
\hline Temperature & Clonal lineage of isolate & Variable $^{\mathrm{a}}$ & Incubator 1 & Incubator 2 & Growth chamber \\
\hline \multicolumn{6}{|l|}{$12^{\circ} \mathrm{C}$} \\
\hline & & IP & $72.00(10.64)$ & $72.75(11.76)$ & $73.50(9.49)$ \\
\hline & & LGR & $0.20(0.02)$ & $0.23(0.05)$ & $0.20(0.02)$ \\
\hline & & SI $\left(\times 10^{5}\right)$ & $1.74(0.47)$ & $1.71(0.65)$ & $1.70(0.32)$ \\
\hline & US-23 & NL & $21.88(6.79)$ & $23.75(15.42)$ & $20.25(4.59)$ \\
\hline & & IP & $74.25(12.80)$ & $75.00(13.22)$ & $75.00(9.62)$ \\
\hline & & $\mathrm{SI}\left(\times 10^{5}\right)$ & $2.95(0.75)$ & $2.89(1.36)$ & $2.88(1.28)$ \\
\hline \multicolumn{6}{|l|}{$18^{\circ} \mathrm{C}$} \\
\hline & US- 8 & NL & $10.33(1.75)$ & $10.83(0.98)$ & 11.50 (1.97) \\
\hline & & IP & $63.00(9.10)$ & $66.00(5.37)$ & $67.00(10.33)$ \\
\hline & & LP & $76.00(9.80)$ & $78.00(6.57)$ & $77.00(9.61)$ \\
\hline & & LGR & $0.23(0.01)$ & $0.24(0.02)$ & $0.24(0.04)$ \\
\hline & & LGR & $0.26(0.01)$ & $0.26(0.01)$ & $0.26(0.01)$ \\
\hline & & $\mathrm{SI}\left(\times 10^{5}\right)$ & $1.74(0.40)$ & $1.75(0.47)$ & $1.72(0.29)$ \\
\hline
\end{tabular}

${ }^{a}$ Variables are the epidemic components that were assessed during the experiments. $\mathrm{NL}=$ number of lesions (lesions $\left./ \mathrm{mm}^{2} / \mathrm{zoospore}\right), \mathrm{IP}=\mathrm{incubation}$ period $(\mathrm{h})$, $\mathrm{LP}=$ latent period $(\mathrm{h}), \mathrm{LGR}=$ lesion growth rate $\left(\mathrm{cm} /\right.$ day), $\mathrm{SI}=$ sporulation intensity $\left(\right.$ sporangia/ $\left./ \mathrm{cm}^{2}\right)$. Shown are the mean and standard deviation of six leaves (two leaves per petri plate) for each variable. No significant differences were detected between incubators and growth chamber. 
release (8.2 zoospores per sporangium) compared to the US-8 isolate ( 7.7 zoospores per sporangium). Four additional leaflets in two plates were inoculated with the same volume of deionized water as controls. Inoculated leaflets were then placed in an incubator at $18^{\circ} \mathrm{C}$ without lights for $14 \mathrm{~h}$ to promote infection (preincubation). After the preincubation period, the petri plates were transferred (at 7:00 a.m.) to different incubators or a growth chamber at constant or fluctuating temperatures, respectively, as described below. Petri plates were kept open (12 h) during the day and closed at night to mimic changes in relative humidity $(\mathrm{RH})$ and leaf wetness. The filter paper was moistened before closing the petri plates without wetting the leaves.

Comparison of growth chamber and incubators at constant temperatures. Two-controlled environment incubators (Thermo Scientific Precision, model 818, Waltham, MA) and a single growth chamber (Percival, model PGC-10, S/N 14732.01.10, Percival Scientific, Inc., Perry, IA) were used for the experiments. The incubators were equipped with fluorescent lights. The growth chamber had both fluorescent and incandescent lights, but only the fluorescent lights were used. All were programmed for a daily cycle of $12 \mathrm{~h}$ light (6:00 a.m. to 6:00 p.m.) and $12 \mathrm{~h}$ dark. Only the growth chamber could be programmed to attain oscillating temperatures. To ascertain that the three chambers performed equally well, preliminary experiments were conducted to compare the five epidemic components of late blight (Table 1), using both isolates of $P$. infestans, in the two incubators and one growth chamber at two constant temperatures $\left(12\right.$ and $\left.18^{\circ} \mathrm{C}\right)$. Both isolates and the water control were evaluated simultaneously and were randomized in each incubator or growth chamber. Three or four petri plates were used with two leaves each. The measured temperatures were not significantly different in the growth chamber and two incubators $\left(12.38^{\circ} \mathrm{C} \pm 0.09\right.$ and $18.375^{\circ} \mathrm{C} \pm 0.03$ in the incubators and $12.40^{\circ} \mathrm{C} \pm 0.22$ and $18.24^{\circ} \mathrm{C} \pm 0.21$ in the growth chamber). The light intensity was 2,200 to $2,4001 \mathrm{~lx}$. The relative humidity in the incubators ranged between 65 and $94 \%$ and that in the growth chamber between 70 and $95 \%$.

Comparison of effects of constant and oscillating temperatures on late blight. Seven different constant temperatures (10, $12,15,17,20,23,27^{\circ} \mathrm{C}$ ) and two amplitudes of oscillating temperatures $\left( \pm 5\right.$ and $\pm 10^{\circ} \mathrm{C}$ ) around the same means were tested for their effects on late blight development. Each average temperature and amplitude combination was tested twice in independent experiments with different inoculation dates, considered true replications. Both of the isolates and the water control were tested simultaneously in each incubator or growth chamber and randomized for each experiment. There were three or four petri plates (pseudo-replicates) with two leaflets for each isolate and the water control within each chamber or incubator. Constant-temperature experiments were conducted in the two controlledenvironment incubators, while the fluctuating-temperature experiments were conducted in the single growth chamber as described above. Each incubator or chamber was programmed for a daily cycle of $12 \mathrm{~h}$ light (6:00 a.m. to 6:00 p.m.) and $12 \mathrm{~h}$ dark. Oscillating temperatures in the growth chamber were programmed using a modified sine-wave equation adjusting the temperature every hour based on the provided maximum and minimum temperature at 1600 and $0400 \mathrm{~h}$, respectively.

$$
T_{\mathrm{H}}=A \operatorname{Sin}(15 \times H+210)+M
$$

where $T_{\mathrm{H}}=$ temperature at hour $H, A=\operatorname{amplitude}\left(T_{\max }-T_{\min }\right) / 2$, $H=$ time in $24 \mathrm{~h}$, and $M=$ mean temperature. The relative humidity in the chamber was set at 60 to $70 \%$ during the day and 90 to $95 \%$ at night.

Measurements of epidemic components. Number of initial lesions per millimeter squared per zoospore (NL), incubation period (IP), latent period (LP), lesion growth rate (LGR), and sporulation intensity (SI) were measured on each leaflet. NL and
IP were assessed every $6 \mathrm{~h}$ starting $24 \mathrm{~h}$ after inoculation. NL was calculated by dividing the number of initial lesions (as determined under a stereo microscope) by the leaf surface area that was in contact with the sporangial suspension and by the number of zoospores applied. The contact area between a droplet and the leaf surface was determined from the $\mathrm{CaCO}_{3}$ deposit remaining after placing $1050-\mu \mathrm{l}$ droplets with a $\mathrm{CaCO}_{3}$ suspension on the abaxial surface of potato leaflets 'Red Lasoda.' Taking the number of zoospores produced per sporangium into account, the number of lesions per square millimeter of contact area per zoospore (NL) was calculated. IP was calculated as hours since inoculation at the time the first lesions were visible under the binocular light microscope. LP was calculated as time required from inoculation to first sporulation observed under the same microscope. For LGR, it was assumed that a lesion grows in a circular fashion and has a constant radial growth rate after IP. LGR was calculated as described by Andrade et al. (1):

$$
\mathrm{LGR}=\frac{\sqrt{\frac{\mathrm{LA}}{\pi}}}{\text { Final eval. }-\mathrm{IP}}
$$

where LA is lesion area. Sporulation intensity was determined at $168 \mathrm{~h}$ (7 days) after inoculation. The lesion area was cut and transferred to a $15-\mathrm{ml}$ vial containing $5 \mathrm{ml}$ of distilled water. The vial was vortexed for $10 \mathrm{~s}$ to dislodge the sporangia. The number of sporangia per milliliter was determined using a hemacytometer and multiplied by the volume of water to determine the sporangia produced up to the sampling time. Sporulation intensity was calculated by dividing sporangia produced by lesion area.

Model fitting and statistical analysis. The original Sharpe and De-Michele model (41) describes how changes in temperature affect the rate of biological processes. The model assumes that the development rate is determined by a single rate-controlling enzyme and that this enzyme is reversibly denatured at high and low temperatures but maintains a constant total concentration independent of temperature. Here, we describe the relationship between the epidemic components of $P$. infestans and average temperature using a modified Sharpe and De-Michele fourparameter model, also known as thermodynamic model, without changing the original theory of the model (39).

$$
r(T)=\frac{\rho 25 \frac{T+273.2}{298} \exp \left[\frac{\Delta H A}{1.987}\left(\frac{1}{298}-\frac{1}{T+273.2}\right)\right]}{1+\exp \left[\frac{\Delta H H}{1.987}\left(\frac{1}{T 1 / 2 H}-\frac{1}{T+273.2}\right)\right]}
$$

where $r(T)=$ development rate, $\rho 25=$ development rate at $25^{\circ} \mathrm{C}$ assuming no enzyme activation, $T=$ temperature $\left({ }^{\circ} \mathrm{C}\right), \Delta \mathrm{HA}=$ enthalpy of activation of the reaction catalyzed by the enzyme $(\mathrm{cal} / \mathrm{mol}), \Delta H H=$ change in enthalpy associated with hightemperature inactivation of the enzyme $(\mathrm{cal} / \mathrm{mol})$, and $T 1 / 2 H=$ temperature at which the enzyme is half active and hightemperature inactive.

For IP and LP, development rate was calculated by using the reciprocal of the time period. The four rate-controlling parameters were estimated for each temperature-amplitude-isolate combination and each replication separately, using Marquardt's method in PROC NLIN in SAS 9.3 (Statistical Analysis System, SAS Institute Inc., Cary, NC). In addition, data predicted from nonlinear regression were compared with the observed data using linear regression. The coefficients of determination from linear regression were used as indicators for the goodness of fit.

For the initial constant temperature test, incubator and growth chamber data were compared with Student's $t$ test for each of the two temperatures separately. For the comparison of constant and oscillating temperatures, we performed multivariate analysis of variance (MANOVA) in PROC GLM on the four rate parameters 
of the thermodynamic model using the three amplitudes $( \pm 0, \pm 5$, and $\pm 10^{\circ} \mathrm{C}$ ) and two isolates as independent variables and the two repetitions as blocks, in order to determine the significance of isolate, amplitude, and their interaction. PROC MIXED was also carried out to confirm our results for individual rate parameters (as MANOVA was not possible in PROC MIXED), but no major differences were detected between the test statistics of the different procedures. When quantification of differences in optimum values of epidemic components was needed for the comparison of constant versus oscillating temperatures, ANOVAs were carried out for the values at the same mean temperatures. To compare the values of an epidemic component of the two isolates under a particular set of temperature conditions, a two-sided paired $t$ test was carried out in Excel.

\section{RESULTS}

Comparison of incubators and growth chamber. At constant temperatures $\left(12\right.$ and $\left.18^{\circ} \mathrm{C}\right)$, there were no significant differences between the two incubators and the growth chamber in any of the late blight epidemic components on individual potato leaves, justifying comparison of data at oscillating temperatures in the growth chamber with those at constant temperatures in the incubators. Although the numbers of lesions induced by the US-8 isolate seemed to be lower in the growth chamber than in the two incubators at $12^{\circ} \mathrm{C}$, this difference was not statistically significant (Table 1) and was probably due to variation among leaves in the experiment at $12^{\circ} \mathrm{C}$ as no such difference was observed at $18^{\circ} \mathrm{C}$.

Nonlinear regressions. The four-parameter thermodynamic model provided a good fit to most of the observed data. When predicted data from nonlinear regression were plotted versus observed data, the coefficients of determination from linear regression ranged from 0.57 to 0.99 for all epidemic components (Table 2 ). The lowest coefficients of determination were observed for number of lesions per zoospore by the US-23 isolate under hightemperature amplitude conditions $\left( \pm 10^{\circ} \mathrm{C}, R^{2}=0.57\right.$ to 0.68$)$.

Effects of average temperatures and their daily amplitudes. Number of lesions per milliliter per zoospore $(N L)$. There was a significant interaction $(P=0.0007)$ between isolate and amplitude for number of lesions formed per zoospore (Table 3). A righthand-skewed curve was observed for the US-8 isolate, with peak lesion formation around $12^{\circ} \mathrm{C}$ for all amplitudes (Fig. 1A). In contrast, the highest number of lesions was observed at $15 \pm 5^{\circ} \mathrm{C}$ for the US-23 isolate (Fig. 1B). For both isolates, a small fluctuation $\left( \pm 5^{\circ} \mathrm{C}\right)$ in temperature around the same mean increased the number of lesions, while the larger fluctuation $\left( \pm 10^{\circ} \mathrm{C}\right)$ in temperature resulted in reduced numbers of lesions. The difference in

TABLE 2. Values of the coefficients of determination $\left(R^{2}\right)$ for linear regressions of predicted data from nonlinear regression on the observed data in two repeated experiments

\begin{tabular}{lcccc}
\hline $\begin{array}{l}\text { Clonal lineage } \\
\text { of isolate }\end{array}$ & Variables $^{\mathrm{a}}$ & $\pm 0{ }^{\circ} \mathrm{C}^{\mathrm{b}}$ & $\pm 5^{\circ} \mathrm{C}^{\mathrm{b}}$ & $\pm 10^{\circ} \mathrm{C}^{\mathrm{b}}$ \\
\hline US-8 & NL & $0.73,0.82^{\mathrm{c}}$ & $0.85,0.91$ & $0.87,0.80$ \\
& IPR & $0.86,0.93$ & $0.89,0.91$ & $0.89,0.84$ \\
& LPR & $0.95,0.98$ & $0.91,0.96$ & $0.95,0.79$ \\
& LGR & $0.81,0.81$ & $0.94,0.94$ & $0.88,0.86$ \\
US-23 & SI & $0.77,0.72$ & $0.90,0.92$ & $0.93,0.88$ \\
& NL & $0.71,0.82$ & $0.93,0.90$ & $0.68,0.57$ \\
& IPR & $0.96,0.98$ & $0.95,0.93$ & $0.93,0.96$ \\
& LPR & $0.98,0.97$ & $0.95,0.97$ & $0.86,0.90$ \\
& LGR & $0.83,0.84$ & $0.87,0.88$ & $0.99,0.98$ \\
& SI & $0.89,0.91$ & $0.97,0.98$ & $0.96,0.96$ \\
\hline
\end{tabular}

${ }^{a}$ Components of epidemic development. NL $=$ number of lesions $/ \mathrm{mm}^{2} / \mathrm{zoo}-$ spore, IP = incubation progression rate/h, LP = latent progression rate/h, LGR $=$ lesion progression rate $(\mathrm{cm} / \mathrm{h}), \mathrm{SI}=$ sporulation intensity $\left(\right.$ sporangia $\left./ \mathrm{cm}^{2}\right)$.

${ }^{\mathrm{b}}$ Amplitudes of daily temperature oscillations.

${ }^{\mathrm{c}}$ Coefficients of determination for two repetitions. peak lesion formation between constant and fluctuating temperatures was significant $(P<0.0001)$ for US-8 only. Specifically, a significant difference was observed when the temperature fluctuation was $10^{\circ} \mathrm{C}$ compared with $0^{\circ} \mathrm{C}$ at a mean temperature of $10^{\circ} \mathrm{C}$ ( $t$ test at one mean temperature; $P<0.0001$ ). The highest number of lesions was at $12 \pm 5^{\circ} \mathrm{C}$ for this isolate.

Incubation period and incubation progression rate (IPR). The reciprocal of incubation period, incubation progression rate, was used for analysis. Overall, there was no significant difference between the isolates $(P=0.6194)$ or interaction between isolate and amplitude $(P=0.1105)$, but the effect of amplitude on IPR was highly significant $(P<0.0001)$ (Table 3$)$. When plotted against temperature, the highest IPR was around $24^{\circ} \mathrm{C}$ under constant temperature conditions (Fig. 2A and B). Under oscillating temperature conditions, the optimum IPR shifted toward lower average temperatures $\left(12\right.$ to $\left.14^{\circ} \mathrm{C}\right)$ such that the curves for constant and oscillating temperatures crossed around $17^{\circ} \mathrm{C}$, the apparent inflection point of the constant-temperature curve. The IPR values increased at larger amplitudes below this point and decreased compared with constant temperatures above it. The effect of temperature on IPR was greater when temperature was constant compared with oscillating, and the IPR curves were flatter as the amplitude increased.

Latent period and latency progression rate $(L P R)$. The latent period and its reciprocal, the latency progression rate, followed a similar pattern in relation to temperature as that of the incubation progression rate (Fig. 2C and D). Again, no significant difference was observed between isolates $(P=0.5394)$, and the amplitude effect was highly significant $(P=0.0042)$ for LPR (Table 3$)$. The shortest latent period or the highest LPR was observed at around $22^{\circ} \mathrm{C}$ under constant temperatures. The LPR curves under constant temperatures showed an inflection point around 16 to $17^{\circ} \mathrm{C}$, where the curves for oscillating temperatures crossed the constant-temperature curve. Below this point, increasing daily amplitudes resulted in faster development rates compared with those at constant temperatures, while at higher mean temperatures, the optimum curves for oscillating temperatures flattened out such that temperature oscillations resulted in reduced LPR values compared with those at constant temperatures. This reduction was greater at $10^{\circ} \mathrm{C}$ than at $5^{\circ} \mathrm{C}$ amplitudes $(P<0.0001)$.

TABLE 3. Multivariate analysis of variance (MANOVA) for the effects of isolate (I), temperature amplitude (AMP), and the interaction between isolate and amplitude on parameter estimates of the thermodynamic model for the epidemic components of late blight on detached potato leaflets (six to eight leaflets per treatment) in two incubators and one growth chamber

\begin{tabular}{llr}
\hline Variables $^{\mathrm{a}}$ & Treatments $^{\mathrm{b}}$ & $P$ value $^{\mathrm{c}}$ \\
\hline $\mathrm{NL}$ & I & 0.0012 \\
& AMP & 0.0001 \\
IPR & I*AMP & 0.0007 \\
& I & 0.6194 \\
& AMP & $<0.0001$ \\
LPR & I*AMP & 0.1105 \\
& I & 0.5394 \\
LGR & AMP & 0.0042 \\
& I*AMP & 0.9582 \\
& I & 0.0010 \\
SI & AMP & $<0.0001$ \\
& I*AMP & 0.0005 \\
& I & 0.0046 \\
& AMP & 0.0022 \\
\end{tabular}

a Variables are the epidemic components of potato late blight. NL = number of lesions $/ \mathrm{mm}^{2} /$ zoospore, IP = incubation progression rate $/ \mathrm{h}, \mathrm{LP}=$ latent progression rate/h, LGR = lesion progression rate $(\mathrm{cm} / \mathrm{h}), \mathrm{SI}=$ sporulation intensity (sporangia/ $\mathrm{cm}^{2}$ ).

b Treatments are P. infestans isolate (I), temperature amplitude (AMP), and the interaction between I and AMP (I*AMP). Isolates were from clonal lineages US- 8 and US-23, and temperature amplitudes were 0,5 , and $10^{\circ} \mathrm{C}$.

c The significance level determined by Wilk's lambda. 
Lesion growth rate $(L G R)$. Under constant temperatures, the LGR was at its maximum at $23^{\circ} \mathrm{C}$ for both isolates (Fig. 3A and B). A shift in optimum temperature from 23 to $20^{\circ} \mathrm{C}$ was observed for LGR when the temperature oscillated by $\pm 5^{\circ} \mathrm{C}$. For LGR, there was a significant interaction between isolate and amplitude $(P=0.0005)$ (Table 3$)$. This interaction was due to a differential effect of temperature oscillations $\left( \pm 10^{\circ} \mathrm{C}\right)$ on the isolates at medium and high mean temperatures. When temperatures oscillated $\pm 10^{\circ} \mathrm{C}$, the LGR for the US- 8 isolate peaked at a lower mean temperature $\left(\approx 19^{\circ} \mathrm{C}\right)$ and then decreased (Fig. 3A), whereas the LGR for the US-23 isolate increased up to $23^{\circ} \mathrm{C}$ and then declined (Fig. 3B). Thus the isolates showed significantly different LGRs $(P<0.0001)$ at a mean temperature of $23^{\circ} \mathrm{C}$ under oscillating $\left( \pm 10^{\circ} \mathrm{C}\right)$ temperatures.

Sporulation intensity $(S I)$. Under constant temperatures, the sporulation intensity per unit of lesion area of the US-8 isolate did not have a clear maximum temperature but decreased sharply at temperatures above $20^{\circ} \mathrm{C}$ (Fig. 3C). The US-23 isolate had a clear maximum SI at a constant temperature of $12^{\circ} \mathrm{C}$ and produced more spores than the US- 8 isolate at higher temperatures (Fig. $3 \mathrm{D})$. There was a significant interaction $(P=0.001)$ between isolate and amplitude (Table 3). Small fluctuations in temperature $\left( \pm 5^{\circ} \mathrm{C}\right)$ resulted in higher numbers of sporangia per unit of lesion area irrespective of mean temperature, except at the temperature extremes. For both isolates, $15 \pm 5^{\circ} \mathrm{C}$ resulted in peak production of sporangia per unit area. Higher-temperature oscillations $\left( \pm 10^{\circ} \mathrm{C}\right)$ had different effects on the sporulation intensities of the two isolates. Under those oscillating conditions, the sporulation intensity of the US- 8 isolate was optimal at $15^{\circ} \mathrm{C}$, while that of the US-23 isolate was optimal at $12^{\circ} \mathrm{C}$.

\section{DISCUSSION}

In this article, we demonstrate that the growth and development rates during different phases of the infection cycle of two isolates of $P$. infestans respond to a wide range of temperatures in the form of typical optimum curves consistent with previous studies $(1,9,19,29)$. Optimum curves were obtained under both constant and oscillating temperatures. Two basic types of curves can be distinguished: curves that are skewed to the left for processes that take place inside plant tissues (colonization during the incubation period, the latent period, and lesion growth) and those that are skewed to the right for processes that are influenced by leaf sur- face temperature (spore germination, initial infection, and sporulation). This distinction has not been mentioned explicitly in the literature but can be gleaned from various figures for in-plant development rates $(1,9,19,29,36)$ and sporulation, germination, and infection $(1,5,28,29,35)$ of low-temperature foliar pathogens.

Although optimum curves were obtained for both constant and diurnally oscillating conditions, the effects of oscillating temperatures differed significantly from those of constant temperatures on all measured epidemic components of potato late blight. During the incubation and latency periods, the late blight development rates were faster under oscillating than under constant conditions at relatively low average temperatures, while these rates were slower under oscillating conditions at relatively high average temperatures. The optimum curves for oscillating and constant temperatures crossed over around $17^{\circ} \mathrm{C}$, which seems to be the inflection point on the left side of the constant-temperature curves. Theoretically, the curves should cross over at the inflection point, because the curve is symmetrical around that point. This would need to be proven mathematically.

In contrast to the clear patterns in incubation and latency progression rates, the results were more complex for the other epidemic components. Small oscillations in temperature $\left( \pm 5^{\circ} \mathrm{C}\right)$ increased sporulation, infection, and lesion growth, especially at low mean temperatures, whereas large oscillations $\left( \pm 10^{\circ} \mathrm{C}\right)$ brought them back at or below the constant temperature values. This difference in response to temperature amplitudes compared to those of the incubation and latency progression rates can be ascribed to the fact that sporulation and initial infection occur mostly at night or in the early morning, when temperatures are low and relative humidities are high. Low temperature optima may be an evolutionary adaptation to night temperatures when sporulation and infection take place. Although the average temperature over a 24-h period is, for example, $15^{\circ} \mathrm{C}$ for processes that take more than 1 day, the actual average during the sporulation and infection period (usually less than $12 \mathrm{~h}$ at night) is lower than $15^{\circ} \mathrm{C}$. A $24-\mathrm{h}$ average temperature of $15^{\circ} \mathrm{C}$ with a daily amplitude of $\pm 5^{\circ} \mathrm{C}$ results in a night temperature closer to the constant temperature optimum, enhancing sporulation and infection. When the amplitude is $\pm 10^{\circ} \mathrm{C}$, the actual average temperature for sporulation and infection is even lower than when the amplitude is $\pm 5^{\circ} \mathrm{C}$ and is now below the constant temperature optimum, explaining the low position of the optimum curve for $\pm 10^{\circ} \mathrm{C}$ compared with that for constant temperatures. Lesion growth rate is also stimulated by
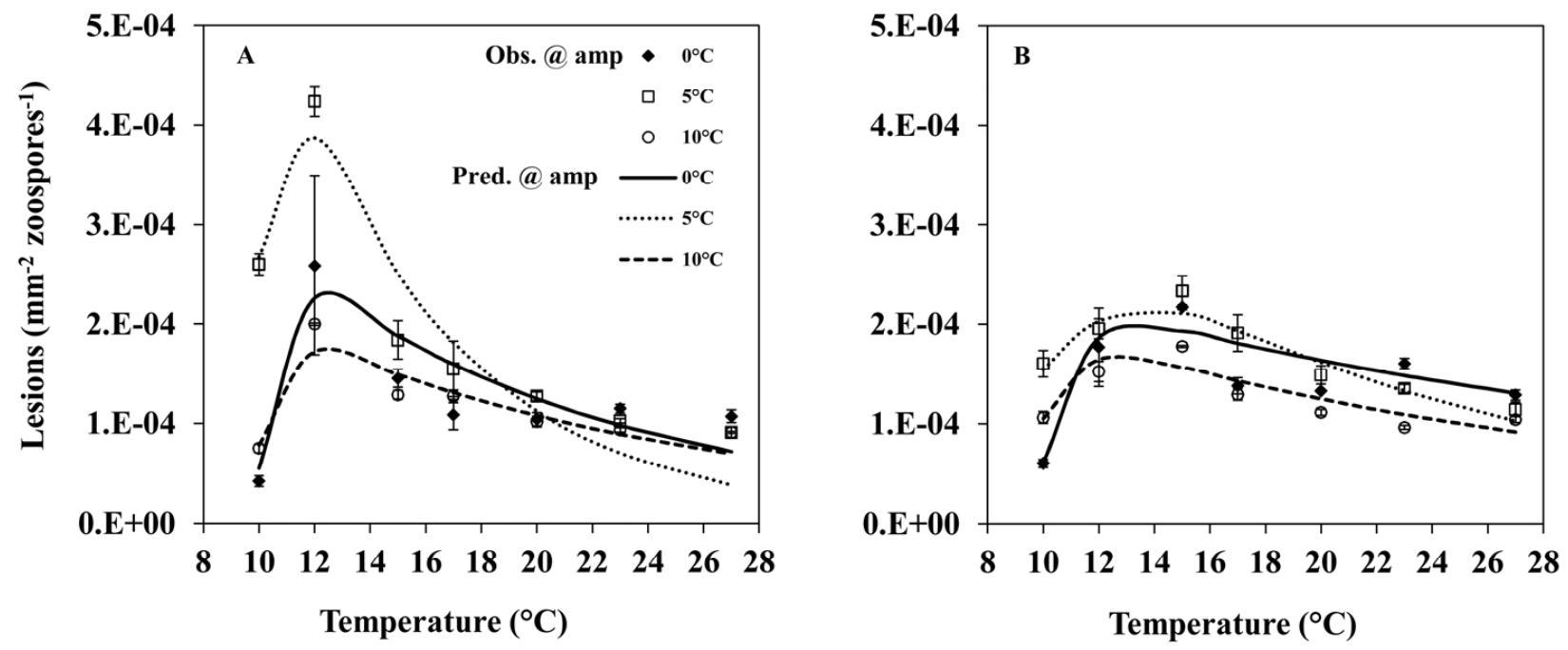

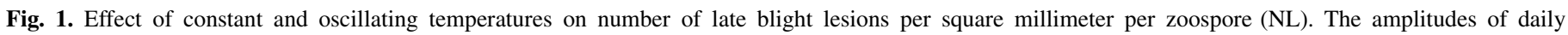

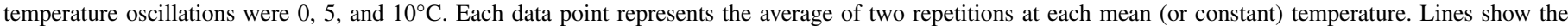

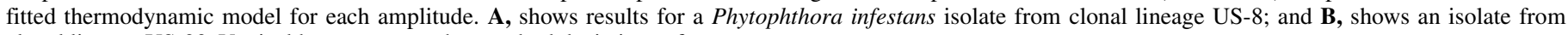
clonal lineage US-23. Vertical bars represent the standard deviations of means. 
small temperature fluctuations $\left( \pm 5^{\circ} \mathrm{C}\right)$ but not by large oscillations $\left( \pm 10^{\circ} \mathrm{C}\right)$. This is different from the incubation and latency progression rates, even though all these processes take place inside the leaves and have optimum curves skewed to the left. Based on our results, we hypothesize that lesion growth rate is affected more by the daytime temperatures than the night temperatures. Consequently, the average temperature at $\pm 10^{\circ} \mathrm{C}$ amplitudes would be above the constant temperature optimum and would be detrimental to lesion growth. This would occur if (visible) lesions primarily increase during the day due to desiccation of infected tissue under high temperature conditions. This could be an explanation for the difference in response to large oscillations between lesion growth rate and incubation or latency progression rate.

The effects of oscillating and constant temperatures on incubation and latent periods were similar for the two isolates used. Clonal lineage US-8 is being gradually replaced by US-23, which produces more devastating epidemics than US-8 $(8,11)$. If the isolates used for this research are representative of the clonal lineages, then the displacement of US- 8 by US- 23 is not due to differences in generation time driven by the incubation and latent period. Rather, the faster epidemic development with US-23 may be explained by differences in sporulation intensity and lesion growth rate. The sporulation intensity of US-23 was higher under both constant and fluctuating $\left( \pm 5^{\circ} \mathrm{C}\right)$ temperatures than that of US-8 in the temperature range of 12 to $20^{\circ} \mathrm{C}$. Moreover, under fluctuating $\left( \pm 10^{\circ} \mathrm{C}\right)$ temperatures, the US-23 isolate had a higher rate of lesion growth at high average temperatures.

To our knowledge, this is the first study examining the effects of diurnal temperature oscillations on the latent and incubation periods, the number of lesions, the lesion growth rate, and sporulation intensity of $P$. infestans. Melhus (28) reported that germination of $P$. infestans spores was faster in cultures at constant temperature compare to those held for $5 \mathrm{~min}$ at $20^{\circ} \mathrm{C}$ and then placed at low temperature. Differences in the incubation period were also reported by Crosier when the pathogen was exposed to three combinations of intermittent high and low temperatures (9). Thus, we have known that developmental rates are affected by average temperatures and temperature extremes, but most epidemiological studies to date have failed to incorporate the notion of diurnal oscillations in temperature. Our results support the hypothesis put forward by Scherm and van Bruggen (37) that the in planta development rates of plant pathogens (with the exception of lesion growth rate) respond less steeply to an increase in average daily temperature as daily amplitudes increase. However, this hypothesis does not hold for processes taking place at the leaf surface like sporulation, spore germination, and initial
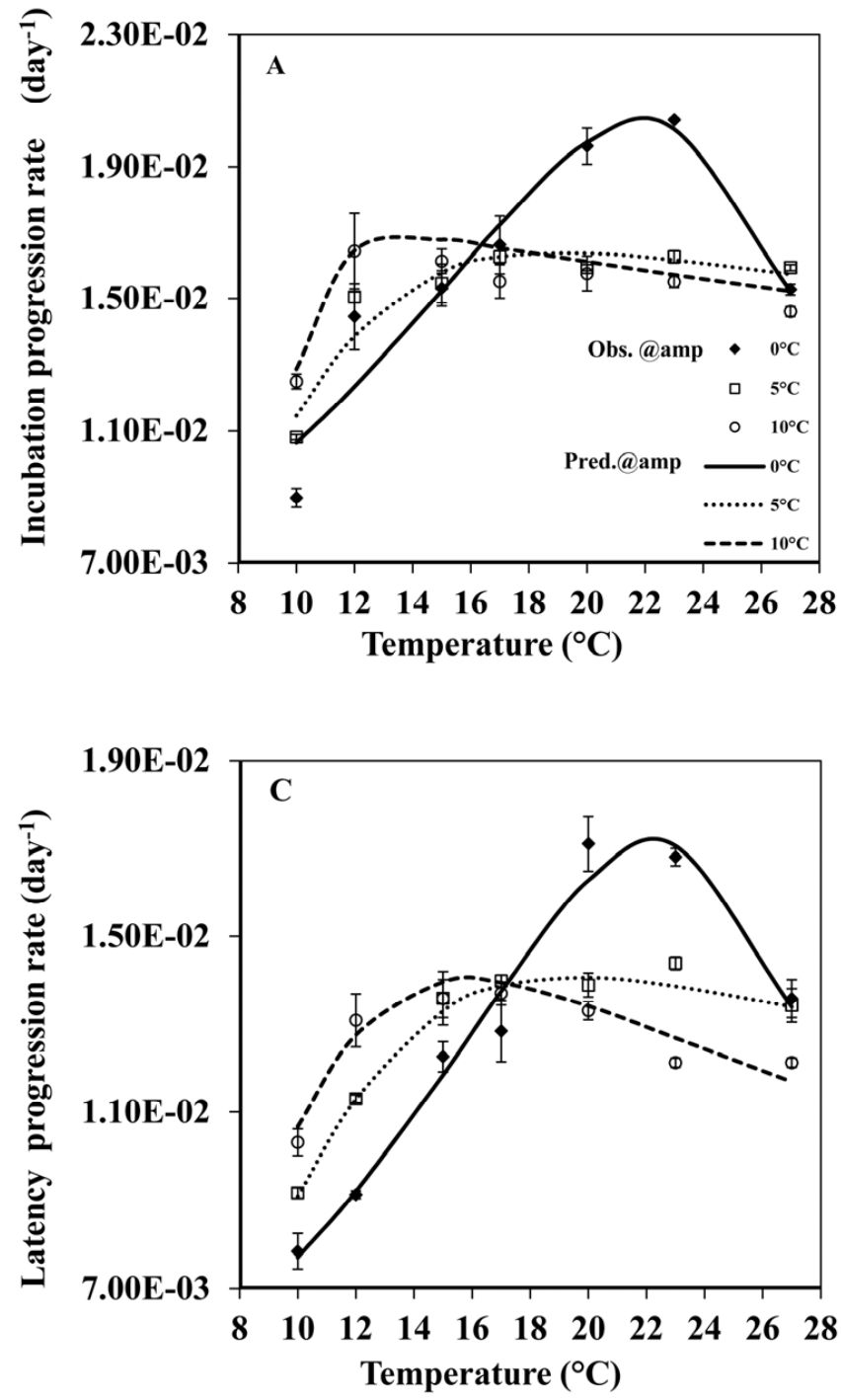
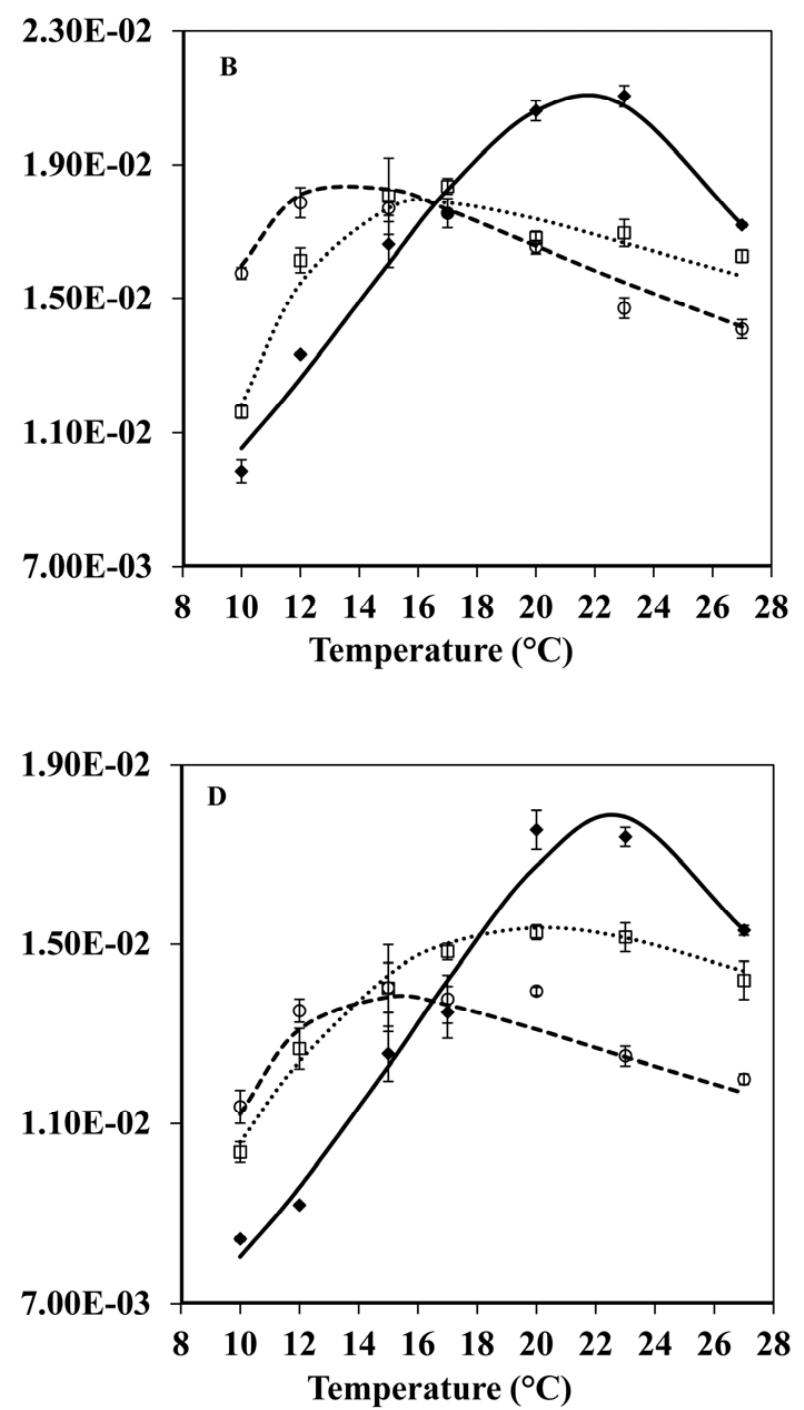

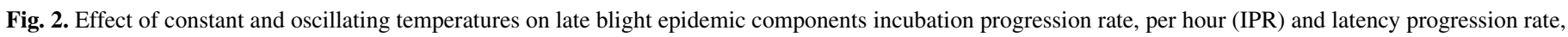

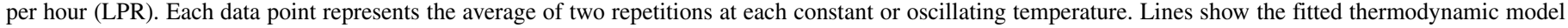

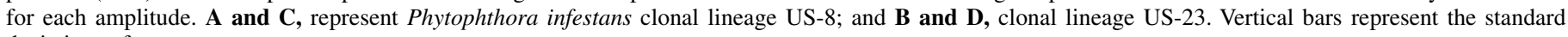
deviations of means. 
infection. Similarly, insect development rates accelerate with increasing magnitude of daily oscillations at low average temperatures and decelerate with increasing amplitudes at high average temperatures $(4,6)$. The response of insects to oscillating temperatures in terms of egg production is similar in complexity to spore production by $P$. infestans $(4,6)$.

Potential mechanisms underlying the different responses to fluctuating versus constant temperatures have been discussed extensively by entomologists, who studied effects of oscillating temperatures on the development rates of eggs and larvae, as well as on oviposition and survival $(4,6,48)$. The differences in development rates under oscillating compared to constant temperatures have been ascribed to the nonlinearity of the optimum curves for insect development rates (48) and, in one case, for fungal plant pathogens (37). These differences in development rates were first described by Kaufmann and are hence called the Kaufmann effect or rate summation effect (48). In addition to the Kaufmann effect, physiological differences under constant versus oscillating conditions have been postulated, in that energy expenditure would be higher (slowing down development) under oscillating than under constant temperatures at mean temperatures close to the optimum of the constant temperature curve $(4,6)$. At relatively low mean temperatures, oscillations generally stimulate insect development as well as egg production, possibly by temporarily exceeding an enzyme activity threshold that may not be reached at low constant temperatures (4). On the other hand, at high average temperatures, oscillations may result in temporary inhibitory conditions resulting in decreased survival as observed for insects (40) and bacteria (40).

The observed differences in the response of epidemic components to oscillating versus constant temperatures will have a profound effect on predictions made for plant disease development under global climate change $(15,37)$. Unfortunately, the uncertainty associated with predictions of diurnal variations in temperature is very large (32). On average, the diurnal amplitudes in temperature are expected to decrease according to predictions by the Intergovernmental Panel on Climate Change (45). However, for some locations, the amplitudes may be underestimated by current climate models. For example, on high plains, the amplitudes may increase under global warming because reduced cloud cover will raise the daily maximum temperature more than the daily minimum temperature, increasing the diurnal temperature amplitude. As the average temperature is generally lower at high than at low altitudes, the late blight development rate will likely be increased when the daily amplitudes are large compared to constant low temperatures, depending on humidity and leaf
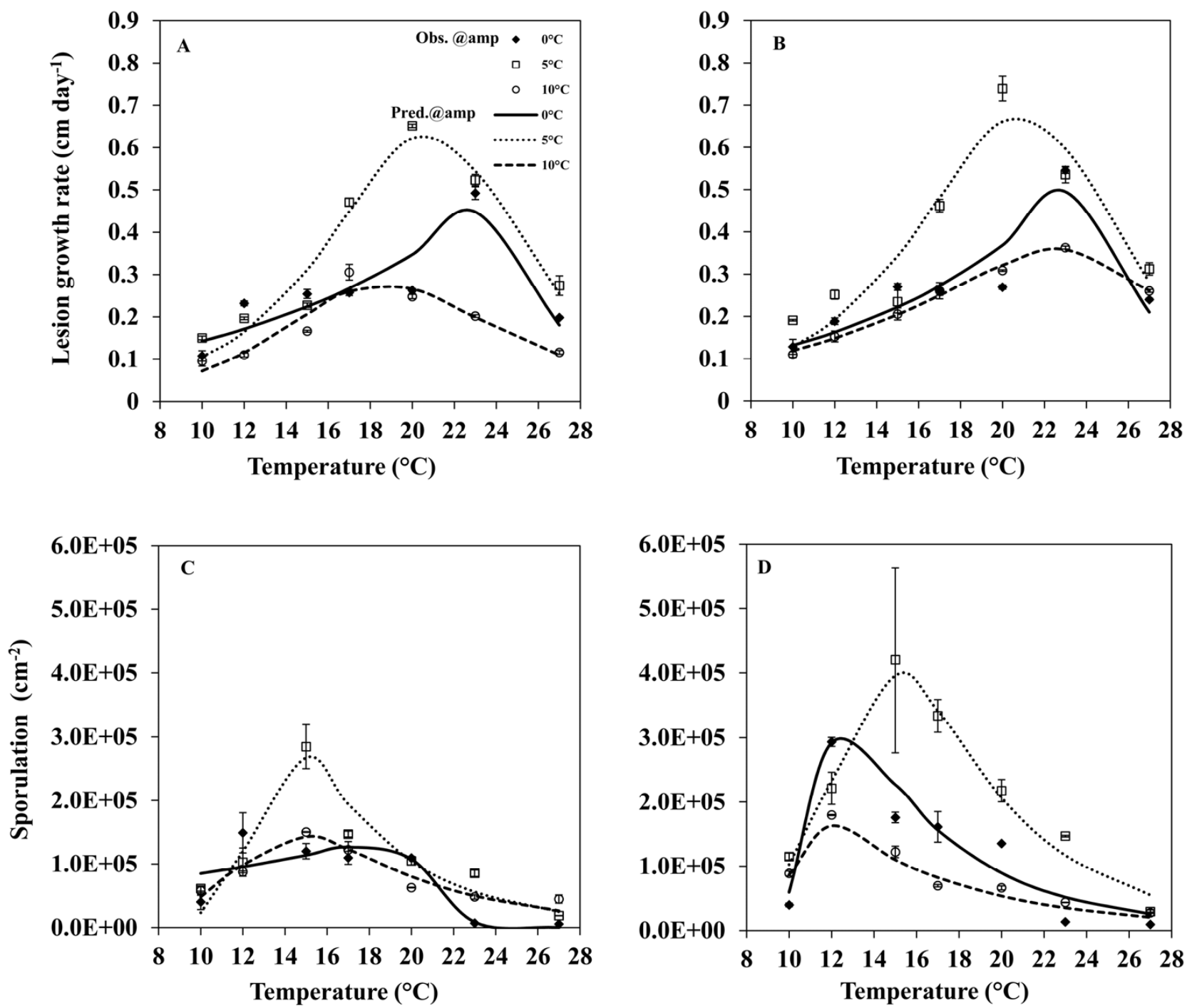

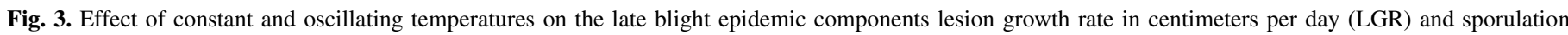
intensity as sporangia per square centimeter (SI). Each data point represents the average of two repetitions at each constant or oscillating temperature. Lines show the fitted thermodynamic model for each amplitude. A and C, represent Phytophthora infestans clonal lineage US-8; and B and D, clonal lineage US-23. Vertical bars represent the standard deviations of means. 
wetness conditions. Thus, our results may be particularly relevant to high-altitude regions. Moreover, the daily temperature oscillations are expected to deviate more from sinusoidal, with maximum temperatures later in the afternoon (25), so that dew periods and high relative humidities will last longer in the morning (38). This might result in faster epidemic development of late blight, but differences in dew periods or relative humidities have not been taken into account during our experiments, as the relative humidity was lowered and increased at fixed time periods each day.

In addition to the absence of realistic day-night changes in relative humidity in our experiments, another shortcoming of this research was that only two incubators and one growth chamber were available, so that not all temperature combinations could be compared simultaneously. However, the treatments were controlled as much as possible: the growth chamber and incubators were adjusted to give the same results under constant temperatures, and the leaflets used for inoculation had the same age because leaflets from plants with different planting dates were used. Moreover, six to eight leaflets were used as pseudoreplicates to minimize variability. Although the preliminary experiments were not repeated, no significant differences were detected between the incubator and growth chamber data using paired $t$ tests.

We assumed that the detached leaf experiments in controlled conditions reflect late blight development under field conditions. We used 20,000 sporangia per milliliter and a 50- $\mu$ drop volume as standard for inoculation, although studies $(23,30)$ suggest that 3,000 to 5,000 sporangia per milliliter and a $10-\mu 1$ drop volume would be sufficient for inoculation. Thus, our infection efficiency (number of lesions per zoospore), may have been underestimated due to on-leaf competition among zoospores. To limit underestimation, lesions were counted under a microscope after the incubation period was complete. Although inoculations were controlled in our experiments, sporulation started on different days as a result of the temperature treatments. Nevertheless, sporulation was measured $168 \mathrm{~h}$ after inoculation for all treatments. Thus, the phase in the sporulation period when spores were harvested varied, as the leaves did not start sporulating at the same time. This could have resulted in an underestimation of the sporulation intensity at mean temperatures optimal for the latency progression rate (around $22^{\circ} \mathrm{C}$ ). This would likely be a more severe problem under constant than under oscillating conditions, because the latent period is shorter under constant than oscillating conditions at a mean temperature around $22^{\circ} \mathrm{C}$. To avoid this problem, multiple samples would need to be taken throughout the sporulation period to estimate spore production over time. However, this would be possible for only a few temperature treatments.

Despite the limitations of our study, it is a critical first step toward understanding the importance of oscillating temperatures for the epidemiology of late blight. We showed that the initial growth and development rates of $P$. infestans respond less drastically to an increase in average temperatures under diurnal oscillations than to a similar increase under constant temperatures at high average temperatures. In contrast, our results suggest that if climate change is accompanied by greater temperature amplitudes at high altitudes with relatively low mean temperatures, the epidemic development rate could be increased. Moreover moderate fluctuations in temperature cause an increase in lesion growth rate and sporulation intensity compared to constant temperatures, especially at relatively low mean temperatures.

It is hard to predict what the implications of these results would be in potato-growing areas at high altitudes, like the Andes, where average temperatures have increased and are expected to increase even further but where rainfall and relative humidity have remained the same over the past 50 years $(31,47)$. Until recently, late blight was limited by relatively low temperatures at high altitudes, but the disease is expanding in those areas (31). A recent metamodel to predict late blight severity based on the accumulation of blight units indicated that there would be little effect of global change on potato late blight risk, except at very high altitudes (44). Diurnal temperature amplitudes were not explicitly taken into account. As a large part of the population in the high Andes relies on potatoes for its livelihood, it is important to accurately predict the risk of potato late blight under the weather conditions expected for specific climatic zones. The results presented in this article will be used for the development of a late-blight simulation model that can be coupled with a potato-crop model under construction in the framework of the Agricultural Model Intercomparison and Improvement Project, or AgMIP (46).

\section{ACKNOWLEDGMENTS}

This study was supported by the US-AID linkage fund project "Collaboration between the International Potato Center (CIP) and the University of Florida (UF) to better understand and prioritize climate change adaptation needs for food security in the Andes." We thank Pamela Anderson, Andre Devaux, and Jorge Andrade-Piedra of CIP and Walter Bowen and Ellen Dickstein of UF for their support. We also thank Shouan Zhang and Bill Fry for providing late-blight-infected leaves from Homestead and clonal lineage US-8 from Pennsylvania, respectively, and Nik Grünwald for genotyping the Homestead isolate.

\section{LITERATURE CITED}

1. Andrade-Piedra, J. L., Hijmans, R. J., Forbes, G. A., Fry, W. E., and Nelson, R. J. 2005. Simulation of potato late blight in the Andes. I: Modification and parameterization of the LATEBLIGHT model. Phytopathology 95:1191-1199.

2. Anonymous. 2007. Pages 1-10 in: Laboratory Manual for P. infestans Work at CIP-Quito. International Potato Centre, Quito, Ecuador.

3. Bebber, D. P., Ramotowski, M. A. T., and Gurr, S. J. 2013. Crop pests and pathogens move polewards in warming world. Nat. Clim. Change 3:985983.

4. Behrens, W., Hoffmann, K.-H., Kempa, S., Gässler, S., and MerkelWallner, G. 1983. Effects of diurnal thermoperiods and quickly oscillating temperatures on the development and reproduction of crickets, Gryllus bimaculatus. Oecologia (Berlin) 59:279-287.

5. Bonde, M. R., Peterson, G. L., and Duck, N. B. 1985. Effects of temperature on sporulation, conidial germination, and infection of maize by Peronospora sorghi from different geographical areas. Phytopathology 75:122-126.

6. Carrington, L. B., Armijos, M. V., Lambrechts, L., Barker, C. M., and Scott, T. W. 2013. Effects of fluctuating daily temperatures at critical thermal extremes on Aedes aegypti life-history traits. PloS ONE 8(3): e58824.

7. Coakley, S. M., Scherm, H., and Chakraborty, S. 1999. Climate change and disease management. Annu. Rev. Phytopathol. 37:399-426.

8. Cooke, D. E. L., Cano, L. M., Raffaele. S., Bain, R. A., Cooke, L. R., Etherington, G. J., Deahl, K. L., Farrer, R. A., Gilroy, E. M., Goss, E. M., Grunwald, N. J., Hein, I., MacLean, D., McNicol, J. W., Randall, E., Olivia, R. F., Pel, M. A., Shaw, D. S., Squires, J. N., Taylor, M. C., Vleeshouwers, V. G. A. A., Birch, P. R. J., Lees, A. K., and Kamoun, S. 2012. Genome analyses of an aggressive and invasive lineage of the Irish potato famine pathogen. PLoS Pathog. 8(10):e1002940.

9. Crosier, W. 1934. Studies in the biology of Phytophthora infestans (Mont.) de Bary. Cornell Univ. Agric. Exp. Stn. Mem. 155. Ithaca, New York.

10. Fry, W. E., and Goodwin, S. B. 1997. Re-emergence of potato and tomato late blight in the United States. Plant Dis. 81:1349-1357.

11. Fry, W. E., McGrath, M. T., Seaman, A., Zitter, T. A., McLeod, A., Danies, G., Small, I. M., Myers, K., Everts, K., Gevens, A. J., Gugino, B., Johnson, S. B., Judelson, H., Ristaino, J. B., Roberts, P., Secor, G., Seebold, K., Jr., Snover-Clift, K., Wyenandt, A., Grunwald, N. J., and Smart, C. D. 2013. The 2009 late blight pandemic in the eastern United States-Causes and results. Plant Dis. 97:296-306.

12. Garcia, B. I., Sentelhas, P. C, Tapia, R. L., and Gerd, S. 2008. Climatic risk for potato late blight in the Andes region of Venezuela. Sci. Agric. 65:32-39.

13. Garrett, K. A., Dendy, S. P., Frank, E. E., Rouse, M. N., and Travers, S. E. 2006. Climate change effects on plant disease: Genomes to ecosystems. Annu. Rev. Phytopathol. 44:489-509.

14. Garrett, K. A., Dobson, A., Kroschel, J., Natarajan, B., Orlandini, S., 
Tonnang, H. E. Z., and Valdivia, C. 2013. The effects of climate variability and the color of weather time series on agricultural diseases and pests, and decision making for their management. Agric. For. Meteorol. 170:216-227.

15. Garrett, K. A., Forbes, G. A., Savary, S., Skelsey, P., Sparks, A. H., Valdivia, C., van Bruggen, A. H. C., Willocquet, L., Djurle, A., Duveiller, E., Eckersten, H., Pande. S., Vera Cruz, C., and Yuen, J. 2011. Complexity in climate change impacts: A framework for analysis of effects mediated by plant disease. Plant Pathol. 60:15-30.

16. Ghini, R., Hamada, E., and Bettiol, W. 2008. Climate change and plant diseases. Sci. Agric. (Piracicaba, Braz.) 65:98-107.

17. Gouache, D., Bensadoun, A., Brun, F., Page, C., Makowski, D., and Wallach, D. 2013. Modelling climate change impact on Septoria tritici blotch (STB) in France: Accounting for climate model and disease model uncertainty. Agric. For. Meteorol. 170:242-252.

18. Harrison, J. G. 1992. Effects of the aerial environment on late blight of potato foliage-A review. Plant Pathol. 41:384-416.

19. Hartill, W. F. T., Young, K., Allan, D. J., and Henshall, W. R. 1990. Effects of temperature and leaf wetness on the potato late blight. N. Z. J. Crop Hortic. Sci. 18:181-184.

20. Harvell, C. D., Mitchell, C. E., Ward, J. R., Altizer S., Dobson A. P., Ostfeld, R. S., and Samuel, M. D. 2002. Climate warming and disease risks for terrestrial and marine biota. Science 296:2158-2162.

21. Juroszek, P., and van Tiedemann, A. 2013. Climate change and potential future risks through wheat diseases: A review. Eur. J. Plant Pathol. 136:21-33.

22. Kato, M., Mizubuti, E. S., Goodwin, S. B., and Fry, W. E. 1997. Sensitivity to protectant fungicides and pathogenic fitness of clonal lineages of Phytophthora infestans in the United States. Phytopathology 87:973-978.

23. Kato, M., and Naito, S. 2001. Change of predominant genotypes of Phytophthora infestans in Tokachi district, Hokkaido, Japan and difference of lesion productivity to the field resistant cultivar 'Matilda' among genotypes. Proc. East Southeast Asia Linkage Gr., Baoding, China, 2000. J. Agric. Univ. Hebei 24(2):11-15.

24. Kaukoranta, T. 1996. Impact of global warming on potato late blight: Risk, yield loss, and control. Agric. Food Sci. Finl. 5:311-327.

25. Knappenberger, P. C., Michaels, P. J., and Schartzman, P. D. 1996. Observed changes in the diurnal temperature and dewpoint cycles across the United States. Geophys. Res. Lett. 23:2637-2640.

26. Li, Y., Cooke, D. E., Jacobsen, E., and van der Lee, T. 2013. Efficient multiplex simple sequence repeat genotyping of the oomycete plant pathogen Phytophthora infestans. J. Microbiol. Methods 92:316-322.

27. Luck, J., Spackman, M., Freeman, A., Trebicki, P., Griffiths, W., Finlay, K., and Chakraborty, S. 2011. Climate change and diseases of food crops. Plant Pathol. 60:113-121.

28. Melhus, I. E. 1915. Germination and infection with the fungus of the late blight of potato (Phytophthora infestans). Agric. Exp. Stn. Univ. Wisc. Res. Bull. 37:1-64.

29. Mizubuti, E. S. G., and Fry, W. E. 1998. Temperature effects on developmental stages of isolates from three clonal lineages of Phytophthora infestans. Phytopathology 88:837-843.

30. Perez, W. G., Gamboa, J. S., Falcon, Y. V., Coca, M., Raymundo, R. M., and Nelson, R. J. 2001. Genetic structure of Peruvian populations of Phytophthora infestans. Phytopathology 91:956-965.

31. Perez, C., Nicklin, C., Dangles, O., Vanek, S., Sherwood, S., Halloy, S., Garrett, K., and Forbes, G. 2010. Climate change in the high Andes:
Implications and adaptation strategies for small-scale farmers. Int. J. Environ. Cult. Econ. Soc. Sust. 6. http://dangles.naturexpose.com/IMG/ file/pdf\%20peer-reviewed/2010_perez_et_al.pdf

32. Ramirez-Villegas, J., Challinor, A. J., Thornton, P. K., and Jarvis, A. 2013. Implications of regional improvement in global climate models for agricultural impact research. Environ. Res. Lett. 8:1-12.

33. Roos, J., Hopkins, R., Kvarnheden, A., and Dixulius, C. 2011. The impact of global warming on plant diseases and insect vectors in Sweden. Eur. J. Plant Pathol. 129:9-19.

34. Scherm, H. 2004. Climate change: Can we predict the impacts on plant pathology and pest management? Can. J. Plant Pathol. 26:267-273.

35. Scherm, H., and van Bruggen, A. H. C. 1993. Response surface models for germination and infection of Bremia lactucae, the fungus causing downy mildew of lettuce. Ecol. Modell. 65:281-296.

36. Scherm, H., and van Bruggen, A. H. C. 1994. Effects of fluctuating temperatures on the latent period of lettuce downy mildew (Bremia lactucae). Phytopathology 84:853-859.

37. Scherm, H., and van Bruggen, A. H. C. 1994. Global warming and nonlinear growth: How important are changes in average temperature? Phytopathology 84:1380-1384.

38. Scherm, H., and van Bruggen, A. H. C. 1994. Weather variables associated with infection of lettuce by downy mildew (Bremia lactucae) in coastal California. Phytopathology 84:860-865.

39. Schoolfield, R. M., Sharpe, P. J. H., and Magnuson, C. E. 1981. Nonlinear regression of biological temperature-dependent rate models based on absolute reaction-rate theory. J. Theor. Biol. 88:719-731.

40. Semenov, A. V., van Bruggen, A. H. C., Overbeek, L., Termorshuizen, A. J., and Semenov, A. M. 2007. Influence of temperature fluctuations on Escherichia coli 0157:H7 and Salmonella enterica serovar Typhimurium in cow manure. FEMS Microbiol. Ecol. 60:419-428.

41. Sharpe, P. J. H., and DeMichele, D. W. 1977. Reaction kinetics of poikilotherm development. J. Theor. Biol. 64:649-670.

42. Shaw, M. W. 2009. Preparing for changes in plant disease due to climate change. Plant Protect. Sci. 45:S3-S10.

43. Solomon, S., Qin, D., Manning, M., Chen, Z., Marquis, M., Avery, K. B., Tignor, M., Miller H. L., eds. 2007. Climate Change 2007: The Physical Science Basis. Contribution of Working Group I to the Fourth Assessment Report of the Intergovernmental Panel on Climate Change. IPCC, Geneva, Switzerland.

44. Sparks, A. H., Forbes, G. A., Hijmans, R. J., and Garrett, K. A. 2014. Climate change may have little effect on global risk of potato late blight. Glob. Change Biol. doi: $10.1111 / \mathrm{gcb} .12587$

45. Stocker, T. F., Qin, D., Plattner, G. K., Tignor, M., Allen, S. K., Boschung, J., Nauels, A., Xia, Y., Bex, V., and Midgley, P. M. 2013. Working Group I Contribution to the Fifth Assessment Report of the Intergovernmental Panel on Climate Change. IPCC, Geneva, Switzerland.

46. Van Bruggen, A. H. C., Jones, J. W., Fernandez, J. M. C., Garrett, K. A., and Boote, K. J. 2014. Crop diseases and climate change in the AgMIP framework. In: Handbook of Climate Change and Agroecosystems, Vol. 3. C. Rosenzweig, ed. Imperial College Press, London, UK.

47. Vuille, M., Bradley, R. S., Werner, M., and Keimig, F. 2003. 20th century climate change in the tropical Andes: Observations and model results. Clim. Change 59:75-99.

48. Worner, S. P. 1992. Performance of phenological models under variable temperature regimes: Consequences of the Kaufmann or rate summation effect. Environ. Entomol. 21:689-699. 